\title{
Straight TO The POINT: \\ HOW PEOPLE ENCODE LINEAR DISCONTINUATIONS ^
}

\author{
Rodrigo I. Mora ${ }^{\star}$ \\ Alejandro Lobos $\star \star \star ~$

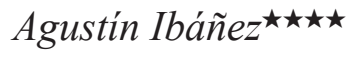

\begin{abstract}
Spatial discontinuations, as those found in cities and buildings, are everyday events. But, how do we encode and classify such misalignments? This is the topic of this paper. Twenty participants were asked to classify a total of 51 icons showing an upward-moving line being misaligned to the right, left and straight down. The results show that subjects were very sensitive to slight discontinuations occurring to vertical lines and that there was not exact symmetry between the left and right axis, meaning that the pieces slightly misaligned to the left were encoded differently than those misaligned to the right
\end{abstract}

Keywords: categorization; spatial misaligments; mental encoding.

^ This work is part of a larger research project (Fondecyt 11100020) funded by Conicyt (Comisión Nacional de Investigación Científica y Tecnológica de Chile).

$\star \star$ Architect. School of Architecture FAAD (Facultad de Arquitectura, Art y Diseño), Universidad Diego Portales. Address: Av. República 180, Santiago, Chile.

E-mail: rodrigo.mora@udp.cl

$\star \star \star$ Psychologist, Cognitive Neuroscience Lab, Universidad Diego Portales.

E-mail: alejandro.lobos.infante@gmail.com

$\star \star \star \star$ Psychologist, Cognitive Neuroscience Lab, Universidad Diego Portales, Instituto de Neurologia Cognitiva (INECO). Miembro de Carrera CONICET, Argentina.

E-mail:agmabaib@gmail.com 


\section{INTRODUCTION}

The way in which people encode visual information has been subject of interest for psychologists and cartographers alike since the thirties. Perhaps the main precedent comes from the work of Köffka (1935) and Köhler (1947), who, under the umbrella of the Gestalt psychology, proposed a series of visual principles that aimed to summarize various cognitive responses of people (of unconscious and automatic nature), to visual stimuli.

According to this view, human perception is driven by one principle, the principle of pragnanz, which organizes what exists in the world in order to make sense of it. "Our reality is not a mere collocation of external facts, but consists of units in which no part exists for itself, where each parts points beyond itself and implies larger wholes" (KOFFKA, 1935, p. 176). This means that human perception does not merely "absorb" external information but that molds and shapes what comes from the environments in order to form plausible meanings. This is achieved by the operation of several "perceptual laws" such as the law of closure, the law of similarity of the law of proximity. However, it is perhaps the law of Good Continuation, which states that visual entities organized along a smooth line or a curve will be perceived as belonging to the same object, the most relevant of these lawsin explaining how people encode linear information. This is because the world is populated by sinuous flows of natural (e.g rivers, coastal borders) or artificial nature (e.g streets, highways), which are represented through different media (digital, paper-based ones) in order to be read by users.

The work of Gestalian theorists has influenced much of map design and research in the twentieth century, especially the one concerned with map production. For example, Thomson and Brooks (2002) suggested that the law of Good Continuation enables map readers to perceive slightly broken paths, similar to those depicted in figure 1 as a continuous entities, rather than isolated ones. In explaining the whole process of map reading, MacEachren and Ganter (1990) contended that maps reading involves the operation of pre-attentive visual processes driven by Gestalt principles which will "inquire" primitive visual schemes, thus triggering a series of visual inspections that give form to plausible representations of maps, which then are further explored by top-down, attentive processes. This idea has been further supported by Stephen Pinker (1990), who argued that images are the resultant of a series of recursive "interrogations" of the brain to visual stimulii.

It has been said that not only visual encoding but real-world experience is shaped by the principle of Good Continuation. Morrison (1981), for example, affirmed that people naturally perceive hierarchies in the real world as a result of the principle of good Continuation, whilst Tomko (TOMKO; WINTER; CLARAMUNT, 2008), argued that hierarchies are naturally perceived by people as a result of the operation of the principle and that this process, in turn, molds how streets are used by persons. 
Despite this evidence, little work has explored how people encode misalignments occurring to lines, a phenomenon that often occurs in the real world, as when a series of sequential spaces forming a street or an alley do not form a continuous entity, as those seen in images $2 \mathrm{a}$ and $2 \mathrm{~b}$, but but a misaligned one. In such circumstances, a person standing in one part of the street or corridor cannot see, or can have just a glance, of what happens in the incoming part of the corridor or street. Figure $2 \mathrm{c}$ exemplifies this situation by showing a commercial passage in which its two segments are partially misaligned.

The problem with such scenario is that it poses a practical and theoretical dilemma. On the practical side, the task involves to give instructions about a destination to a another person in which he or she has to move along this misaligned space. What kind of descriptions should we employ to describe these scenarios? Should we ignore these misalignments and say, for instance, "move straight", or should we caution our listener and say that such space is slightly discontinued? On the theoretical side, the problem arises with the scarce evidence on this kind of reasoning existing in the literature. This paper aims to advance in the latter direction.
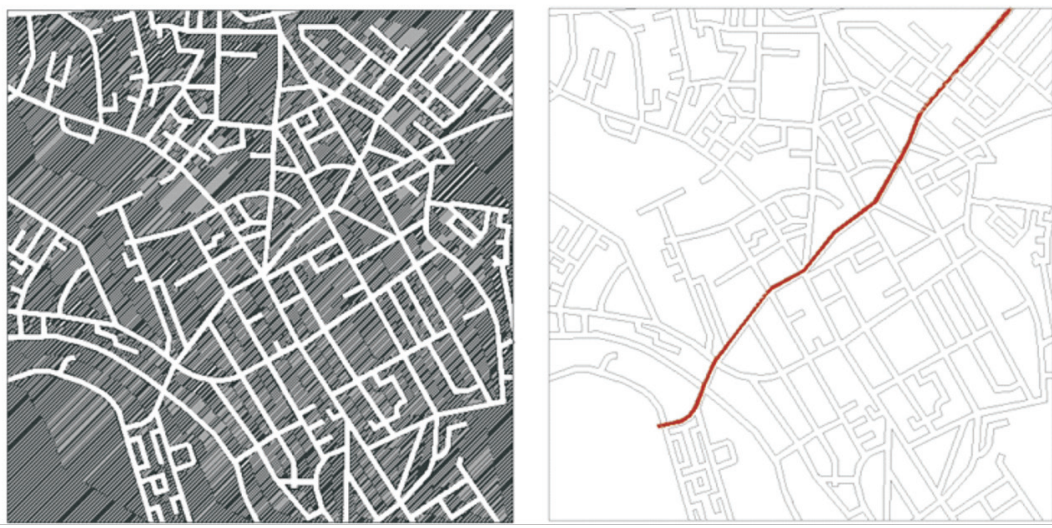

Figure 1: the operation of the Principle of Good Continuation. Source: the author
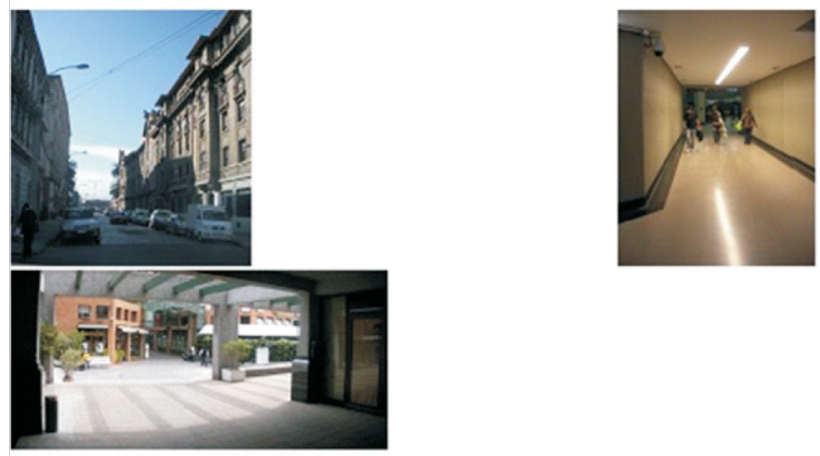

Figure $2 \mathrm{a}$ and $2 \mathrm{~b}$ (left and centre respectively): two examples of continuous scenarios. Figure $2 \mathrm{c}$ (left): a semi continuous urban alley 
Figures $2 \mathrm{a}$ and $2 \mathrm{~b}$, showing a typical street in a downtown area of a city and a large corridor in a campus, serve to illustrate this idea.

\section{Previous WORK}

This work stems from a the series of experiments made by Klippel and Montello $(2004,2007)$ that attempted to understand how people encode turn directions. Klippel and Montello asked people to classify 122 types of turns, ranging from the sharp left to the sharp right. The items appeared in a disorganized way on a screen and people had to move them to the right in order to form as many groups as they wanted. The results showed that people encode turn directions in a complex way, for there is no symmetry between the upper and lower sides of the horizontal axis, nor between the right and left side of the vertical axis.

With the objective of expanding Klippel and Montello's findings, this paper presents and investigation on how people encode linear misalignments. To date, this is a rather unexplored area, although recent research has shown that spatial discontinuations heavily affect how space is explored by people (HILLIER, 1996; CONROY-DALTON, 2003; WERNER; SCHINDLER, 2004; MORA, 2007; CARLSON et al., 2010). Hillier, for example, has suggested that minor spatial discontinuations of space that might difficult for people to infer global properties of spatial systems might cause the emergence of "urban ghettos", where no person apart from residents passes through. Conroy-Dalton, showed that by slightly moving the pieces of a virtual world (without changing any other feature of it), the entire structure of exploration became less structured and unpredictable (CONROY-DALTON, 2003). Werner and Schindler (2004) and Mora (2007), showed that slight spatial misalignments affect, respectively, wayfinding performance in buildings. Finally, a recent paper by Carlson and colleagues (2010) suggest that wayfinding behavior depend, to a great extent, in the existence of continuous visual access to incoming spaces.

\section{Method}

\section{Participants}

Twenty participants ( 7 males, 13 females) students of an introductory course of psychology at the Diego Portales University, in Santiago, participated voluntarily in this experiment. Most of them were in their early twenties (mean age 21.2 years, $\mathrm{SD}, 2.78$ years).

\section{Materials and Design}

In order to test how people encode different levels of misalignments, a series of intersections were designed. These, shown in figure 3 , depict a vertical (line V) and a horizontal line (line H) encountering at $90^{\circ}$. The first of these intersections (top) showed no misalignment between the upper and lower segments of line V. Since both lines had the same width, the area of overlapping of lines 
$\mathrm{H}$ and $\mathrm{V}$ was a square (see grey space in the centre). From a perceptual point of view, this means that a person standing in the lower part of line $\mathrm{V}$ would have a total continuity of vision to the upper part of this line. However, as a consequence of moving the upper segment to the right, the area of overlapping between lines $\mathrm{H}$ and $\mathrm{V}$ progressively decreases, meaning that only a fraction of the space in the upper part of line $\mathrm{V}$ is visible from the lower part. Three levels of partial misalignments were considered here. The five remaining icons (rightmost section of figure 2) show different levels of discontinuity of line V. As it can be seen, now a person standing in the lower part of line $\mathrm{V}$ would not be capable of perceiving what happens in the upper part of it.

Figure 4 shows the 51 icons used in this experiment. Like in the previous example, these icons depicted the intersection of two lines, one horizontal and one vertical, which were symmetrically misaligned to the right and left in eight different levels. The top row of figure 2 shows these misalignments. As it can be seen, whereas piece $\mathrm{N}^{\mathrm{o}} 1$ and piece $\mathrm{n}^{\mathrm{o}} 17$ showed a major misalignment of the vertical line to the left and to the right respectively, piece $\mathrm{N}^{\circ} 9$, showed no misalignment at all between the upper and lower segments of the vertical line. The pieces in between these poles showed slight to major misalignments to the left and right respectively. The remaining 34 pieces of the sample, depicted in the second and third row of figure 2 have the same type of misalignments on the vertical line. However, unlike the first row in which all streets had the same width, in rows 2 and 3 the vertical and horizontal street had a different width. For example, from piece 18 to piece 33, the horizontal street was wider than the vertical street, whilst from piece 34 to piece 51 the opposite was the case. For the sake of simplicity, pieces 1 to 17 will be named type 1 icons, pieces 18 to 34 , type 2 and pieces 35 to 51, type 3 icons.

The introduction of a different-size mechanism changed the distribution of partial and misalignments pieces in the last row, for a wider vertical street increased the area or overlapping between the lower and upper segments of line V. The introduction of a double-size mechanism was aimed at testing whether people mentally "inhabited" the pieces in order to classify their misalignment. Contemporary cognitive approaches have suggested that spatial understanding is deeply embodied have suggested that people use their own bodied to encode spatial categories (TVERSKY, 2003; TVERSKY; MARTIN, 2009). Seeing it this way, it was thought that people would position themselves in the lower part of the vertical line in order to assess how much of the coming line could be seen, and that this assessment might be important to classify the pieces. It was thus expected that people would classify the pieces according to how much they could (potentially), see ahead, rather than strictly attending to the metric size of the misalignment. 


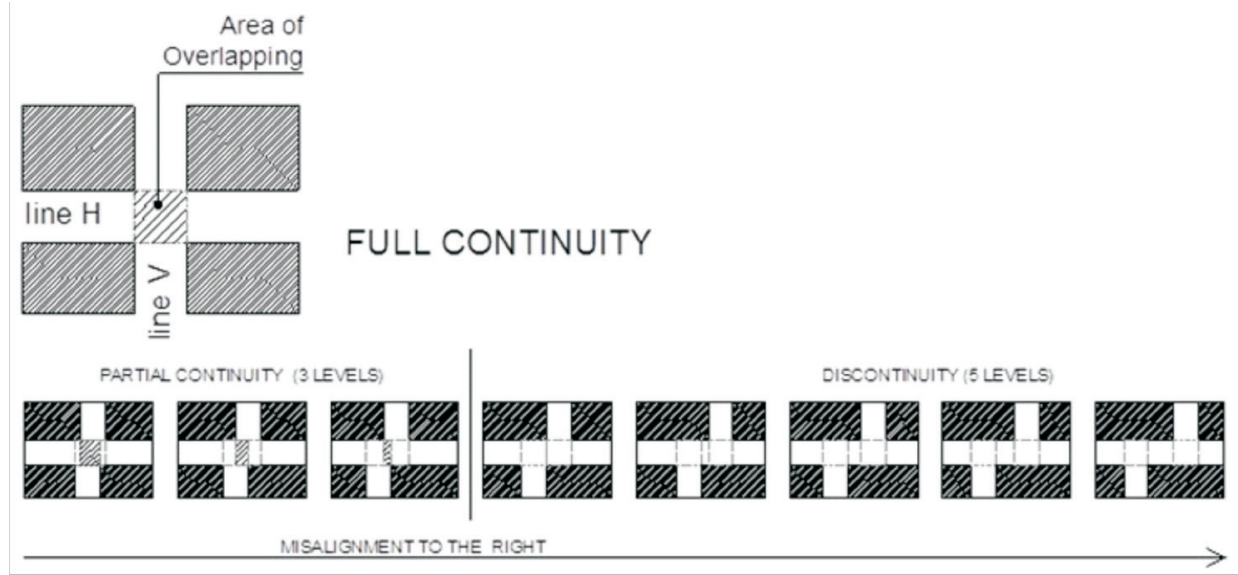

Figure 3: levels of misalignment of a generic intersection

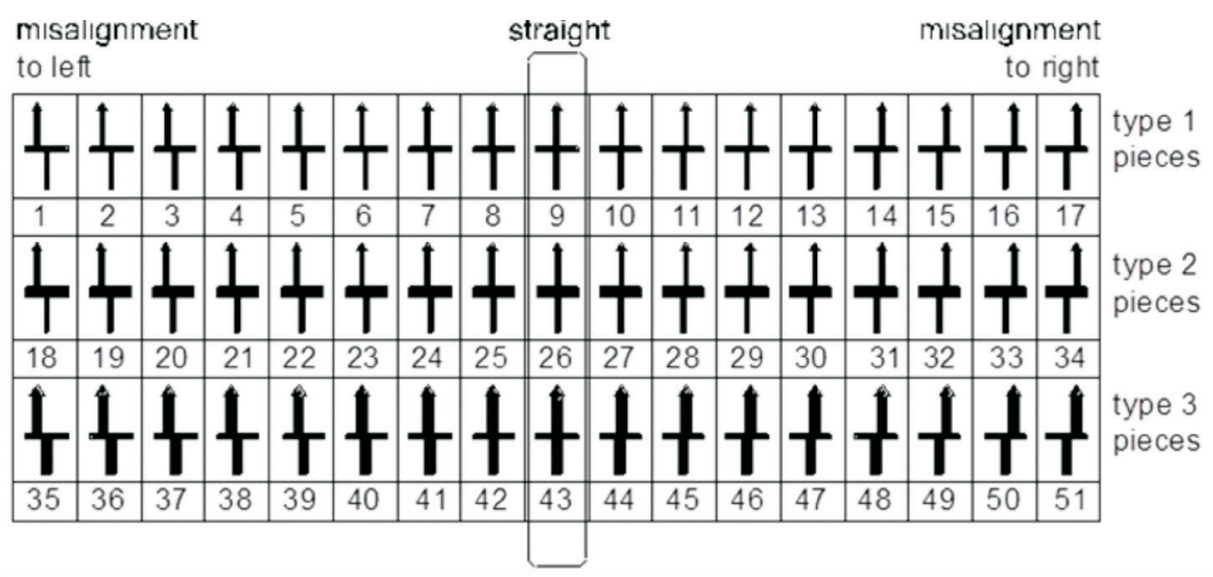

Figure 4: the set of icons used in this experiment

\section{Procedure}

The experiment took place on the premises of the School of Psychology at the Diego Portales University, in Santiago. Subjects participated voluntarily in the experiment and were tested individually. ${ }^{1}$ One of the researchers informed them that the experiment aimed to understand how people encode and classify discontinuations occurring to lines.

Participants received a cupboard of about $18 \times 27 \mathrm{cms}$ containing and a set of 51 icons, as figure 5 shows. They were asked to move the icons to the right-hand side area of the cupboard, and to make groups how many groups they wanted. In order to do so, subjects had to insert a series of sticks in the right-hand side area of the cupboard. Although no time restriction was set to complete the task, most participants completed the experiment in about 10 minutes. 


\section{Data analysis}

People's responses were analyzed by constructing a 51x51 similarity matrix, corresponding to the number of icons used in this experiment. This method permitted the researchers to code all possible similarities between two icons, for any pair of icons was coded " 0 " if its two items were not placed in the same group. The overall similarity of two items was achieved by summing over all the similarity matrices of the 20 individuals. For example, if two icons (e.g. pieces $\mathrm{N}^{\circ}$ 9 and $\mathrm{N}^{\mathrm{o}} 10$ ) were placed into the same group by all participants a total of twenty " $1 \mathrm{~s}$ " was obtained for the pair, resulting on an overall score of 20 for the pair 9-10.

\section{Results}

The similarity matrix was subjected to a hierarchical cluster analysis in SPSS. The resulting dendogram, shown in figure 7, defined five main groups. The first of them was composed of 11 icons and corresponded to what might be called the STRAIGHT category (see figure 8 ). Although this category had the three types of icons of this experiment (1,2 and 3), there was no exact symmetry between the icons located on the left and on the right of the straight axis (pieces 9, 26 and 43). This means that group 1 was slightly inclined to the left. Group 2 (twelve icons) and Group 3 (14 icons), showed the vertical-moving line misaligned to the left and right respectively. Finally, Group 4 and Group 5 (six items each), show a double-sized vertical line misaligned to the left and right respectively. Figure 8 shows these groups

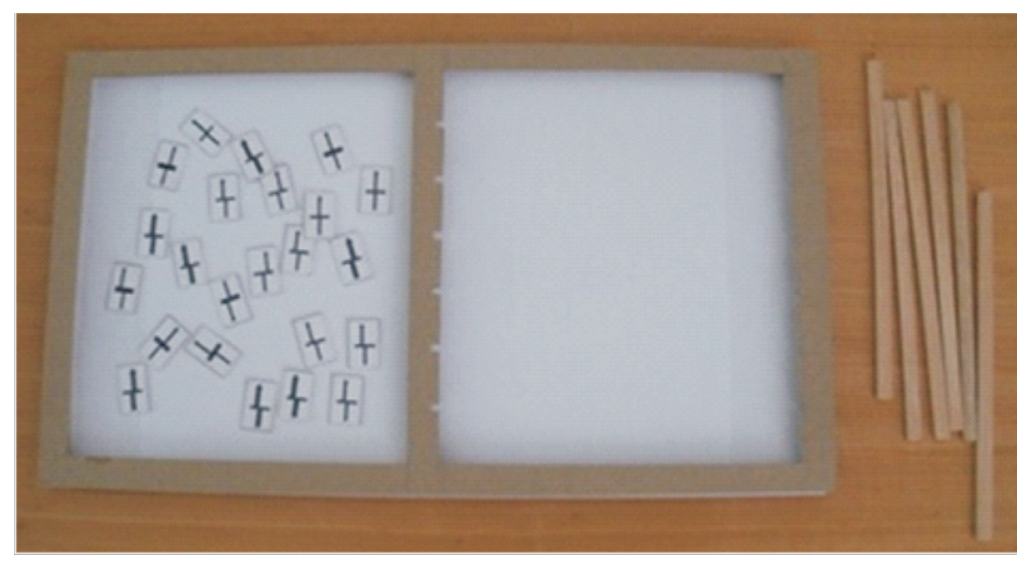

Figure 5: the cupboard pad used in this experiment 


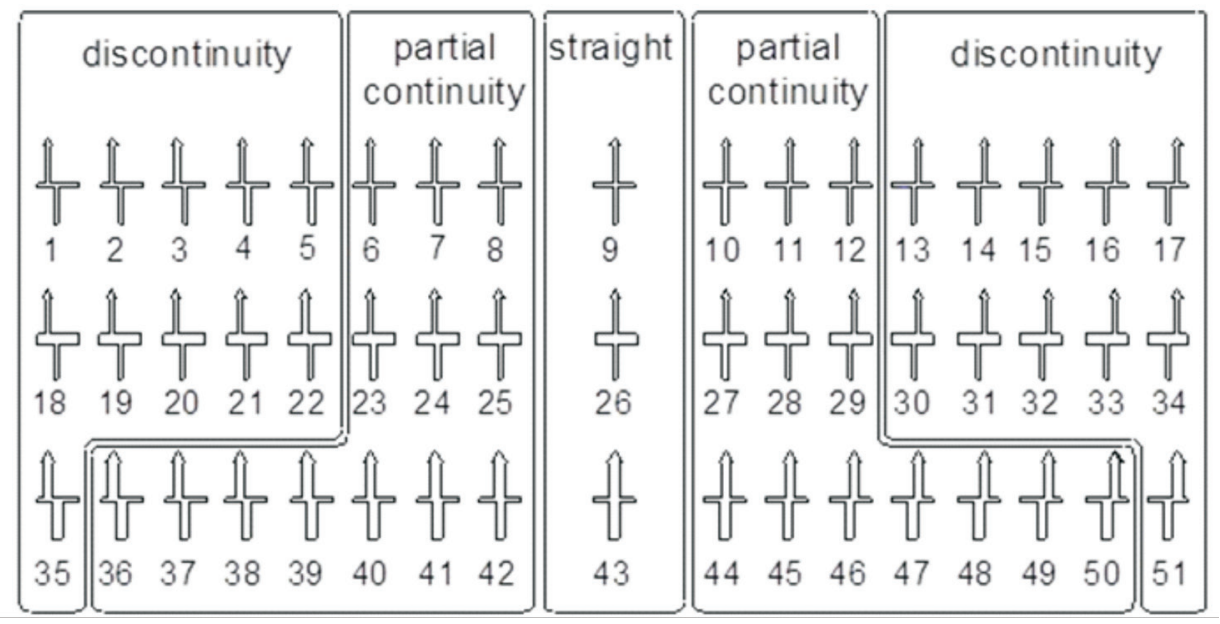

Figure 6: variations in the type of continuities between the icons as a result of enlarging street $\mathrm{V}$

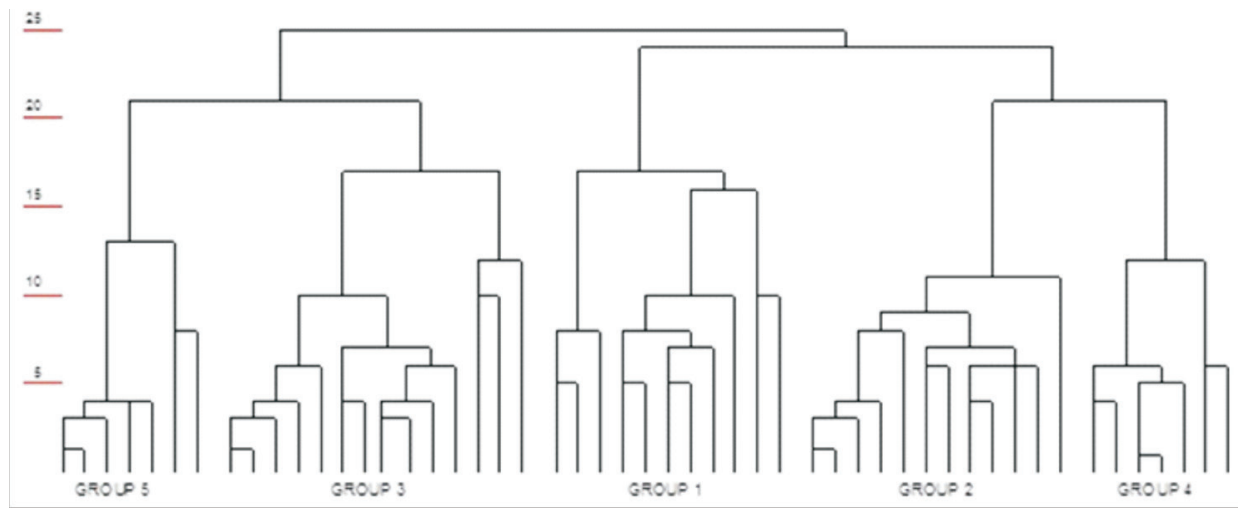

Figure 7: the cluster analysis of the 51 icons

\section{Discussion}

There are various aspects of interest in these results. The first is that the concept of STRAIGHTNESS was not strictly related to the partially continuous icons (see figure 4), that is, the icons in which the vertical and horizontal streets overlapped as it was initially hypothesized, but to a more complex mechanism. In fact, the STRAIGHT category (as it might could called, since subjects did not verbally encode the categories), was circumscribed to those icons in which the area of overlapping was very discrete, and permitted to see most of the upper segment of line V. It seems therefore, that people defined a "perceptual threshold" when classifying linear misalignments, one that seemed to respond, primarily, to metric factors, and secondarily to an embodied reasoning. This means that people classified as STRAIGHT the pieces permitting to see most of the coming environment, as shown by the reduced pool of pieces in group 1, but at the same 
time, did not use purely this criteria to classify the pieces, as demonstrated by the fact that some of the type 3 icons that potentially permitted to visually connect the upper and lower parts of line V (e.g. pieces 39, 40, 41, 45, 46 and 47), were not included in group 1.

A possible explanation to this result might be that participants only "paid attention" to the vertical line when completing the task, thus neglecting what happened to the horizontal line. As a result, the misalignment occurring to line $\mathrm{V}$ in groups 4 and 5 was perceived differently as the discontinuation occurring to the same line in groups 2 and 3. However, this does not explain why the same effect occurred to pieces 42, 43 and 44, the three last icons of group 1 . Here it will be suggested that the concept of STRAIGHTNESS prevails over other aspects like line width providing there is no noticeable difference in the misalignment line V.

Another aspect of interest regards the asymmetry of groups 1 and 2 with respect to the three "straight" pieces (icons 8, 26 and 43). In fact, while group 3, composed of 14 icons, group 2, is composed of twelve pieces. To some extent, this result is in line with recent research on angular classification made by Klippel and Montello (2007), who showed that angular encoding is not strictly symmetric, but has certain degrees of variation the right and left.

From a cognitive perspective, these results seem to support the idea that human reasoning is inherently categorical (LAKOFF; JOHNSON, 1999), wand that categories are part of one's experience of the world. Various authors have demonstrated that categorical thinking is anchored to our own bodies (TVERSKY, 1981), in the sense that body axes as coordinate references to convey directions and make angular estimations. Further, it has been demonstrated that categorical thinking occurs at other spheres of the human mind. For example, individuals tend to encode spatial information in high-order structures which leads them to systematically exaggerate, omit, rotate, align and displace places and regions according to their position within super ordinate regions (TVERSKY, 1992).

Future work may solve some of the limitations of this study by enlarging the sample size, including a more diverse pool of participants, and making it possible for participants to define a larger number of categories. An interesting line of research is to study how people verbally describe the observed categories. Likewise, it might be noteworthy to study whether the higher "sensitivity" towards minor deviations occurring to the right disclosed in this experiment are related to people's inclination to choose right positions in real-world circumstances, as stated by previous studies (SCHARINE; McBEATH, 2002; WEYERS et al., 2006). In the long run, to better comprehend how people classify slight and minor misalignments of lines might also serve to improve verbal or written instructions, whose use is growing steadily as a result of the increasing availability of mobile phones and geographic information devices. 


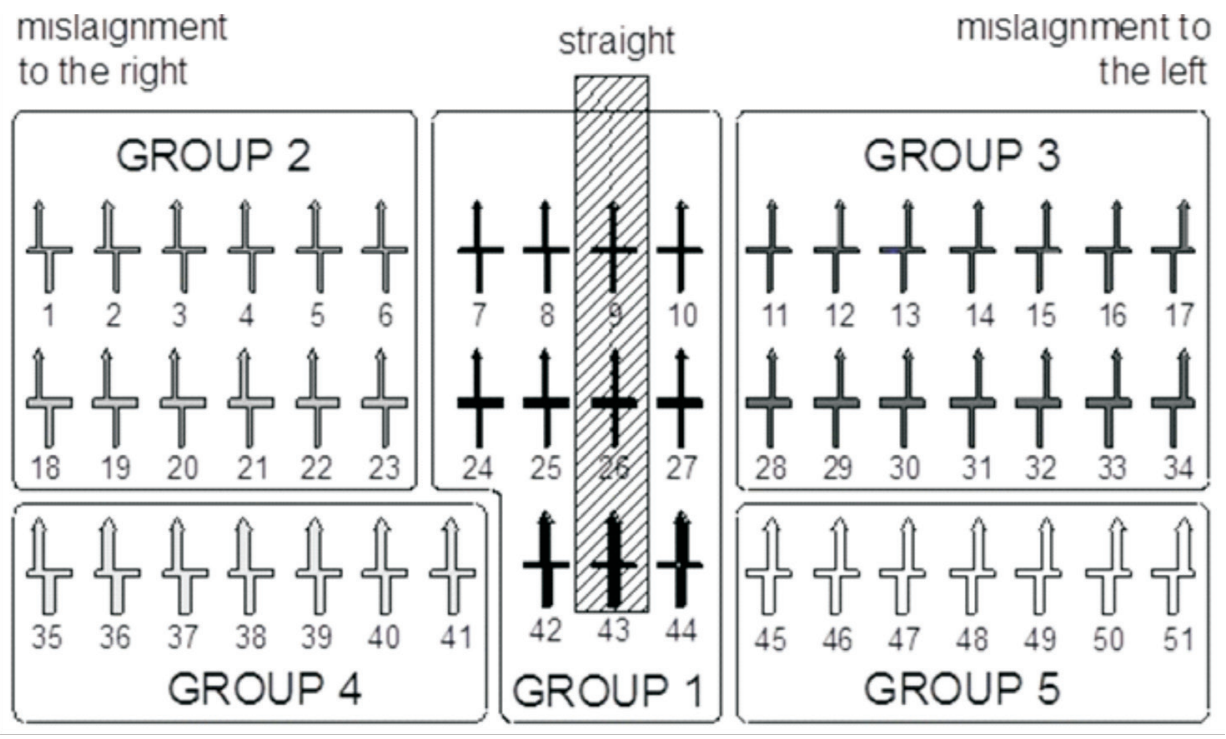

Figure 8: the five main groups made by participants

\section{Note}

Since this was an exploratory experiment, no signed permission was asked of participants, However, they were informed that they could terminate the experiment whenever they wanted.

\section{REFERENCES}

CARLSON, L. et al. Getting Lost in Buildings. Current Directions in Psychological Science, [S.1.], v. 19, n. 5, p. 284-289, Oct. 2010.

CONROY-DALTON, R. The secret is to follow your nose. Route path selection and angularity. Environment and Behavior, v. 35, n. 1, p. 107-131, 2003.

HILLIER, B. Space is the machine. Cambridge: Cambridge University Press, 1996.

KLIPPEL,A.; MONTELLO, D. R. On the robustness of mental conceptualizations of turn direction concepts. In: INTERNATIONAL CONFERENCE ON GEOGRAPHIC INFORMATION SCIENCE, 3., 2004, Adelphi, Maryland. Proceedings... Adelphi: University of Maryland, 2004. p. 139-141.

KLIPPEL, A.; MONTELLO, D. R. Linguistic and nonlinguistic turn directions concepts. INTERNATIONAL CONFERENCE ON SPATIAL INFORMATION THEORY, COSIT, 8., 2007, Melbourne, Australia. Proceedings... Lecture Notes in Computer Science 4736, Sydney: Springer, 2007. p. 354-372. 
KÖFFKA, K. Principles of Gestalt psychology. London: Kegan Paul, Trench, Trubner and Co., 1935.

KÖHLER, W. Gestalt psychology: an introduction to new concepts in modern psychology. New York: Liveright, 1947.

LAKOFF, G.; JOHNSON, M. Philosophy in the flesh: the embodied mind and its challenge to Western thought. New York: Basic Books, 1999.

MacEACHREN, A.; GANTER, J. H. A pattern identification approach to cartographic visualization. Cartographica, [S.1.], v. 27, n. 2, p. 64-81, 1990.

MORA, R. Unpacking the visual variables of spatial confusion. In: INTERNATIONAL SPACE SYNTAX SYMPOSIUM, 6., Istambul. Proceedings... Istambul: I.T.U. Faculty of Architecture, June 2007.

MORRISON, A. Using the Department of Transport's database road databank to produce route planning maps. The Cartographic Journal, [S.1.], v. 18, n. 2, p. 91-95, 1981.

PINKER, S. A theory of graph comprehension. In: FRIEDLE, R. (Ed.) Artificial intelligence and the future of testing. Hillsdale, NJ: Lawrence, 1990. p. 73-126.

SCHARINE, A. A.; McBEATH, M. K. Right-handers and Americans favor turning to the right. Human Factors, [S.1.], v. 44, n. 2, p. 248-256, Summer 2002.

THOMSON, R. C.; BROOKS, R. Exploiting perceptual grouping for map analysis, understanding and generalization: the case of road and river networks. Lecture Notes in Computer Science 2390. New York: Springer, 2002. p. 148-157. .

TOMKO, M.; WINTER, S.; CLARAMUNT, Ch. Experiential hierarchies of streets. Computers, Environment and Urban Systems, [S.1.], v. 32, n. 1, p. 41-52, 2008 .

TVERSKY, B. Distortions in memory for maps. Cognitive Psychology, [S.1.], n. 13, p. 407-433, 1981.

TVERSKY, B. Distortions in cognitive maps. Geoforum, v. 23, n. 2, p. 131138, 1992.

TVERSKY, B. Structures of mental spaces: how people think about space. Environment and Behavior, v. 35, n. 1, p. 66-80, Jan. 2003.

TVERSKY, B.; MARTIN B. Embodied and disembodied cognition: Spatial perspective-taking. Cognition, [S.1.], v. 110, n. 1, p. 124-129, 2009. 
WERNER, S.; SCHINDLER, L. E. The role of spatial reference frames in architecture: misalignment impairs way-finding performance. Environment and Behavior, v. 36, n, 4, p. 461-482, July 2004.

WEYERS, P. et al. How to choose a seat in theatres: Always sit on the right side? Laterality, v. 11, n. 2, p. 181-193, Mar. 2006.

Received: May 30, 2012 Accepted on: December 14, 2012 